\title{
The Study of Physicochemical Properties and Nutrient Composition of Mari Olive Leaf Cultivated in Iran
}

\author{
Yadollah Jabalbarezi Hukerdi ${ }^{1}$, Mohammad Hassan Fathi Nasri ${ }^{1}$, Ladan Rashidi ${ }^{2 *}$, Mehdi Ganjkhanlou ${ }^{3}$ \\ 1- Department of Animal Science, Faculty of Agriculture, University of Birjand, Birjand, Iran \\ 2- Department of Food and Agriculture, Standard Research Institute, Iranian National Standards Organization (INSO), Karaj, Iran \\ 3- Department of Animal Sciences, Faculty of Agriculture and Natural Resources, University of Tehran, Karaj, Iran
}

\section{A B S T R A C T}

Background and Objectives: According to recent research, olive leaf (OL) has demonstrated significant properties, including antibacterial, antiviral, anticancer, gastro protective and cardio protective properties. The aim of this study was to investigate the chemical composition, and fatty acid composition (FAC) of OL of Marry variety cultivated in Jiroft province of Iran. This study also attempts to identify and quantify the polyphenolic compounds of OL of Mari.

Materials and Methods: The content of dry matter (DM), crude protein (CP), ash, fat ether extract (FEE), acid detergent fiber (ADF) and neutral detergent fiber (NDF) of OL, FAC, type and amount of polyphenol compounds, antioxidant activity (AA\%), total phenol, tannin, flavonoid contents (TPC, TTC, and TFC, respectively), were determined, all procedures were performed according to the reference methods.

Results: The content of DM, and CP, Ash, FEE, ADF, and NDF of OL obtained 94.7 $\pm 0.08(\%)$, and 13.08 $\pm 0.06,6 \pm 0.7$, $3.9 \pm 0.28,32.48 \pm 0.56,40.6 \pm 0.26$ (DM\%), respectively. The amounts of TPC, TTC and TFC of OL were obtained

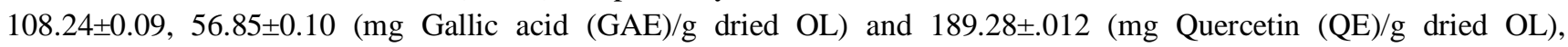
respectively. Results showed that oleuropein was the dominant polyphenol $(8306.9 \mu \mathrm{g} / \mathrm{g}$ of dried OL). The AA\% of OL extract was obtained $61 \% \pm 0.9 \%$. The FAC of OL was determined by gas chromatography (GC) and the results showed linoleic acid $(27.2 \pm 0.33 \%)$ followed by oleic acid $(21.8 \pm 0.40 \%)$ as the most abundant unsaturated FAs found in the OL, respectively.

Conclusions: These results demonstrated that OL is a rich source of natural and bioactive compounds, which can be used in the food industry, animal feed, and so on for improving the nutritional value and functionality.

Keywords: Olive leaves, Polyphenol compound, Antioxidant activity, Fatty acids profile

\section{Introduction}

Olive leaf (Olea europaea) is one of the medicinal plants, which is considered as a good and cheap source of natural antioxidants. Among the different parts of the olive tree, the olive leaf is one of the richest sources of the phenolic compounds (1). Oleuropein and their metabolites, including tyrosol and hydroxy tyrosol are the most abundant phenolic compounds known in the olive leaf. There is a linear relationship between the oleuropein content of olive leaf and the amount of its antioxidant activity (2). One of the most significant properties of oleuropein is its high antioxidant activity, leading to acting as a free radical receptor (3). These properties were approved using in vitro and in vivo experiments by researchers. In these experiments, the ability of oleuropein and its extract containing higher amounts of oleuropein for the neutralization of radical 2, 2'-diphenyl-1-picryl hydrazyl (DPPH) was higher than that of butylated hydroxy toluene (BHT) as a synthetic antioxidant (4, 5). It was reported that oleuropein has different properties, including antibacterial, antiviral, antitumor, blood pressure and blood lipids reducing factor, anticancer and cardioprotective properties (6$9)$. However, the increase of consumer demand for fresher and more natural food, "preservative-free" products has led the food industry to consider the 
incorporation of natural antioxidants in a range of products. The use of natural antioxidants in food industry has the advantage of being more acceptable by the consumers as these are considered as "non chemical". In addition, they do not require safety tests before being used (10). Because of the consumer emphasis on synthetic food additives for their harmful effects on body, it should not be habituated and the natural production should be used (11). Some of the related institute of human health (Great Britain Nutrition Foundation, 1992; Department of Health, 1994) have paid attention to the beneficial effects of food containing polyunsaturated fatty acids (PUFA). It was reported that the suitable ratio of omega 6 to omega 3 of fatty acids food can make improve the condition of human health. Many studies were performed for the increase of these fatty acids in the animal products (meat and milk) via changes in omega 3 fatty acids quantity in the animal diets. (12). For instance, Abbeddou et al. (2011) investigated the modification of milk fatty acid composition of awassi sheep by feeding of agro-industrial byproducts (13). They reported that using olive leaf led to an increase of omega 3 fatty acids and conjugated linoleic acid (C18:2 c9, t11) amounts in awassi sheep milk. Also, Botsoglou et al. (2010) found that the use of OL in turkey diet improved the meat quality due to the reduction of lipid oxidation in the raw and cooked meat (14).

The aim of this study was to investigate the physochemical properties, fatty acid composition, identification and quantification of the main content of polyphenol compounds, TPC, TTC, TFC and AA\% of the selected OL, as named Mari variety, which is a national variety cultivated in Jiroft province of Iran.

\section{Materials and Methods}

Materials: Acetonitrile, orthophosphoric acid, and methanol with the HPLC grade were purchased from the Merck Company (Germany, Berlin). 2, 2Diphenyl-1-picrylhydrazyl (DPPH) was purchased from Sigma-Aldrich (United States of America, Boston). The reference standard of FAME mixture (C4-C24), 5- $\alpha$-Cholestane, mono-, di-, triglycerides, Cholesterol, $\beta$-Sitosterol, Stigmasterol, vanillic acid, vanilin, caffeic acid, quercetin, oleuropein, tyrosol, cinnamic acid, luteolin, catechin, gallic acid, apigenin, and ferulic acid were purchased from Sigma-Aldrich Company. Other materials, including, hexane, glacial acetic acid, chloroform, potassium iodide (KI), Folin-Ciocalteu reagent, and Hanus solution were also purchased from the Merck Company (Germany).

\section{Methods}

Olive leaf sampling: Fresh olive leaf (O. europaea L., Marry variety) was collected from an olive farm of Jiroft province of Iran. OLs were washed with water (three times), dried at room temperature, then finely grounded (Arthur Hill Thomas Co., Philadelphia, PA). Then, powders were kept in a dark, and dry bottle until further analysis.

Analysis of olive leaves: Dried powder of OL was analyzed for the determination of dry matter (15), ash (16), crude protein (17) and crude fat diethyl ether extraction (18) according to the AOAC methods. In addition, acid detergent fiber and neutral detergent fiber were determined according to the described method by Van Soest et al., 1991 (19). (19). For determination of NDF, $0.5 \mathrm{~g}$ sample in $100 \mathrm{ml}$ of neutral detergent solution plus $50 \mu 1$ of heat stable amylase (dietary fiber kit; Sigma catalogue Number A3306) was heated to boiling temperature. Sodium sulfite $(0.5 \mathrm{~g})$ was added at this point. Sample was heated for $1 \mathrm{~h}$ and filtered on a coarse sintered glass crucible or Whatman 54 paper (Whatman, Clifton, NJ). The ash content was reported or excluded from the NDF. Also, for determination of ADF, 1g sample was weighed and $100 \mathrm{~mL}$ of cold (room temperature) acid detergent solution was added. The mixture was refluxed for 60 minutes from onset of boiling. Then the content was filtered on the coarse sintered glass crucible or Whatman 54 paper (Whatman, Clifton, NJ). Samples were ground through a $1 \mathrm{~mm}$ screen.

Preparation of extract: For this purpose, $1 \mathrm{~g}$ of $\mathrm{OL}$ powder was weighted in a 250 flask and $10 \mathrm{~mL}$ of the methanol solution $(80 \%)$ was added to the flask content. Then, flask was put in the ultrasonic bath for 15 minutes. The extract was centrifuged at $5000 \mathrm{rpm}$ for 5 minutes. The OL was filtered with a Millipore membrane filter $(0.45 \mathrm{~mL})$ prior to HPLC analysis. Analysis of OL extract polyphenol compounds was performed at $280 \mathrm{~nm}$ at room temperature. The detection of tyrosol, p-coumaric acid, quercetin, caffeic acid, vanillin, catechin, vanillic acid, gallic acid, oleuropein, rutin, luteolin, luteolin 7-Oglucoside, apigenin and cinammic acid was made by comparison of their retention times and UV-vis spectra with those obtained from standards (COI/T.20/Doc No 29 - 2009) (20). 
Calibration curves of each polyphenol compound: For detection and quantification of each polyphenol compound of OL, calibration curves of each phenolic compound were obtained by preparation of their stock solutions with concentration of $1 \mathrm{mg} / \mathrm{mL}$. Then, concentrations of $10,20,30,40,50$, and $100 \mu \mathrm{g} / \mathrm{mL}$ were prepared by dilution of each stock solution. Twenty $\mu \mathrm{L}$ of each prepared concentration was injected to HPLC-9100 (Young Lin, Korea) equipped with UV detector.

HPLC condition: Separation of polyphenol compounds was carried out using HPLC (Young Lin, South Korea), equipped with a reversed phase C18 analytical column C18-WP (Column: $4.6 \mathrm{~mm} \times 250$ $\mathrm{mm}, 100 \mathrm{~A}^{\circ}, 5 \mu \mathrm{m}$ ), and UV detector (at $280 \mathrm{~nm}$ ). Mobile phases consisted of deionized water with $2 \%$ orthophosphoric acid (solvent A), and acetonitrile and methanol (50:50 (v/v) (solvent B) at a flow rate of 1.0 $\mathrm{mL} / \mathrm{min}$. The following gradient was applied:

\begin{tabular}{ccc}
\hline Time (minute) & $\mathrm{A} \%$ & $\mathrm{~B} \%$ \\
\hline Initial & 96 & 4 \\
40 & 50 & 50 \\
45 & 40 & 60 \\
60 & 0 & 100 \\
70 & 0 & 100 \\
72 & 96 & 4 \\
82 & 96 & 4 \\
\hline
\end{tabular}

DPPH assay: The antioxidant activity of the OL extract was determined according to the method developed by Arabshahi et al. (2007) (21). For this purpose, $1 \mathrm{~mL}$ of DPPH methanolic solution $(0.135$ $\mathrm{mM}$ ) was mixed with $3 \mathrm{~mL}$ of OL extract. Then, the mixture was vigorously vortexed and kept for 30 minutes at $25^{\circ} \mathrm{C}$ in darkness. The absorbance of extract was measured at $517 \mathrm{~nm}$ by UV/VIS spectrometer (Lambda 25-Perkin Elmer, USA). Then, the percentage of DPPH scavenging relative to control was calculated using the following equation. All experimentations were done in triplicate.

DPPH scavenging activity $(\%)=($ Absorbance of ControlAbsorbance of sample)/ (Absorbance of control) $\times 100$

Determination of Total Phenolic Content (TPC): TPC of OL extract was determined by colorimetric assay. Briley, $200 \mu \mathrm{L}$ of an aliquot OL extract was mixed with deionized water $(800 \mu \mathrm{L})$ as well as Folin-Ciocalteu reagent $(100 \mu \mathrm{L})$, respectively. The mixed solution was then incubated for three minutes in room temperature. Then, $300 \mu \mathrm{L}$ sodium carbonate
$\left(\mathrm{Na}_{2} \mathrm{CO}_{3}\right)(20 \%(\mathrm{w} / \mathrm{v}))$ was added and incubated for 2 hours in darkness at $25^{\circ} \mathrm{C}$. The absorbance of the extract was determined at $765 \mathrm{~nm}$ with $\mathrm{UV} / \mathrm{vis}$ spectrometer. The calibration curve of Gallic acid (GA) standard was obtained in the range $0-100 \mathrm{mg} / \mathrm{L}$ and calibration curve equation was obtained $\mathrm{Y}=$ 0.0154X, $\mathrm{R}_{2}=0.9936$. Total phenolic content was expressed in $\mathrm{mg}$ GA equivalent to per $\mathrm{g}$ of dry matter (22).

Determination of Total Tannins Content (TTC): For this purpose, $100 \mu \mathrm{L}$ of aliquot $\mathrm{OL}$ extract was added to $750 \mu \mathrm{L}$ distilled water and then $500 \mu \mathrm{L}$ Folin-Ciocateu reagent as well as $1000 \mu \mathrm{L}$ of sodium carbonate $\left(\mathrm{Na}_{2} \mathrm{CO}_{3}\right)(35 \%(\mathrm{w} / \mathrm{v}))$ was added. Then, the mixture was shaken and diluted with distilled water and then incubated for 30 minutes at $25^{\circ} \mathrm{C}$. The absorbance of OL extract was determined at $725 \mathrm{~nm}$ by UV/Vis. As already mentioned above, calibration curve of the GA standard solution was prepared in the range 0 - $100 \mathrm{mg} / \mathrm{GA}$. Finally, TTC was expressed as GAE/g dry matter (22).

Determination of Total Flavonoid Content (TFC): Total flavonoid content was determined using the method described by Mohammed et al. (2015) (19). An aliquot of $0.5 \mathrm{~mL}$ of $2 \% \mathrm{Alcl}_{3}$ prepared in ethanol solution was added to $0.5 \mathrm{~mL}$ of sample solution, followed by measuring the absorbance at $420 \mathrm{~nm}$, after $1 \mathrm{~h}$ of incubation at room temperature. Total flavonoid content was calculated as quercetin equivalent $(\mathrm{mg} / \mathrm{g})$ from a calibration curve.

Fatty Acid Composition (FAC) of OL: For determination of FAC of OL, $0.1 \mathrm{~g}$ of powder was weighted and $0.1 \mathrm{~mL}$ alcoholic potassium hydroxide (11.2 $\mathrm{g} \mathrm{KOH}$ in $100 \mathrm{~mL}$ pure methanol) was added to the sample. Then, $1 \mathrm{~mL}$ hexane was added to the suspension and mixed. The mixture was vortexed for $1 \mathrm{~min}$ and put in the water bath at $50^{\circ} \mathrm{C}$ for $15 \mathrm{~min}$. Finally, the transparent upper layer of the suspension was separated and poured in the vial for the analysis by GC (Young Lin 6500, Korea). The column of GC was Cp-sil 88 capillary column $(60 \mathrm{~m} \times 0.25 \mathrm{~mm}$, $0.25 \mathrm{~m}$ film thickness, Agilent Technologies, USA). The detector and injector temperatures were set at $320^{\circ} \mathrm{C}$ and $280^{\circ} \mathrm{C}$, respectively. The Initial oven temperature was set in $165^{\circ} \mathrm{C}$ and was linearity increased to $210{ }^{\circ} \mathrm{C}$ at a rate of $5{ }^{\circ} \mathrm{C} / \mathrm{min}$. Peaks were identified by comparing their retention times with those of an authentic standard mixture.

Statistical Analysis: All data were statistically analyzed with SPSS version 11statistical software 
package and expressed as means \pm standard deviation (SD). All tests were performed in triplicate. Statistical significance was declared at $\mathrm{p}<0.05$. In addition, all tests were performed in Microsoft Excel.

\section{Results}

Results of determination of physicochemical properties, including DM, CP, Ash, FEE, ADF and NDF content, of Mari olive leaf from Jiroft province of Iran are shown in Table 1. In addition, results of determination of Total phenolic (TP), flavonoid (TF) and tannin (TT) content of OL methanolic extract are presented in Table 1.

Table1. Chemical composition and major classes of phytochemicals in Mari olive leaf

\begin{tabular}{lc}
\hline Chemical Composition $(\%)$ & OL \\
\hline Dry matter & $94.70 \pm 0.08$ \\
Fat Ether extract & $3.90 \pm 0.28$ \\
Protein & $13.08 \pm 0.06$ \\
Ash & $6.00 \pm 0.70$ \\
Acid detergent fiber & $32.48 \pm 0.56$ \\
Neutral detergent fiber & $40.60 \pm 0.26$ \\
\hline Phytochemicals & $108.24 \pm 0.09$ \\
Total phenol (mgGAE/g) & $189.28 \pm 0.12$ \\
Total flavonoid (mgQ/g) & $56.85 \pm 0.10$ \\
Total tannin $(\mathrm{mgGAE} / \mathrm{g})$ & \\
\hline Antioxidant activity & $61.00 \pm 0.10$ \\
DPPH $(\%)$ & \\
\hline
\end{tabular}

Furthermore, type and amount of detected polyphenolic compounds of $\mathrm{OL}$ are presented in Table 2. Results showed that oleuropein followed by Cinnamic acid and then hydroxytyrosol were predominant phenolic compounds in Mari OL.

Table 2. Polyphenolic compound of OL

\begin{tabular}{lcc}
\hline Polyphenolic compounds & $(\%)$ & $\mu \mathrm{g} / \mathrm{g}$ dried \\
& & $\mathrm{OL}$ \\
\hline Hydroxy tyrosol & $4.10 \pm 0.01$ & - \\
Tyrosol & $0.90 \pm 0.02$ & 11.82 \\
Gallic acid & $0.90 \pm 0.03$ & 10.46 \\
Catechin & $1.80 \pm 0.11$ & 21.52 \\
Syringic acid & $\mathrm{N} . \mathrm{D}$ & - \\
Caffeic acid & $1.60 \pm 0.14$ & 14.40 \\
Vanillin & $1.00 \pm 0.04$ & 5.14 \\
Vanillic acid & $1.60 \pm 0.03$ & 17.98 \\
P. Cumaric acid & $4.00 \pm 0.15$ & 8.81 \\
Ferulic acid & $11.80 \pm 0.21$ & 100.45 \\
Rutin & $3.10 \pm 0.18$ & - \\
Verbascoside & $10.40 \pm 0.30$ & - \\
Oleuropein & $40.50 \pm 0.51$ & 8306.90 \\
Cinnamic acid & $4.40 \pm 0.08$ & 6.26 \\
Quercetin & $1.60 \pm 0.02$ & 16.31 \\
Luteolin & $1.30 \pm 0.03$ & 18.05 \\
Apigenin & $0.70 \pm 0.02$ & 6.13 \\
Others & $10.30 \pm 0.10$ & - \\
\hline N.D:Not & &
\end{tabular}

N.D: Not detected
The fatty acids composition of Mari OL is presented in Table 3. The results showed the major saturated fatty acids in OL was palmitic acid (C16:0) [(23.3 \pm 0.15$) \%]$. In addition, the known unsaturated fatty acids were linoleic acid (C18:2) [(27.2 \pm 0.33$)$ $\%$, oleic acid (C18:1) [(21.8 \pm 0.40$) \%]$ and linolenic acid (C18:3) [(12.5 \pm 0.20$) \%]$. The results showed that Mari OL had high amount of unsaturated fatty acids [(65.9 \pm 0.93$) \%]$.

Table 3. Fatty acids composition of Mari OL

\begin{tabular}{lc}
\hline Fatty acids compound & $\begin{array}{c}\text { Fatty acids amount } \\
(\%) \pm \text { SD }\end{array}$ \\
\hline C14:0 & $1.90 \pm 0.03$ \\
C14:1 Cis & $0.40 \pm 0.01$ \\
C16:0 $0: 1$ Cis & $23.30 \pm 0.15$ \\
C17:0 & $2.10 \pm 0.04$ \\
C18:0 & $0.80 \pm 0.01$ \\
C18:1 Cis & $3.60 \pm 0.45$ \\
C18:2 Cis $18: 3$ Cis & $21.80 \pm 0.40$ \\
C20:0 $027.20 \pm 0.33$ \\
C20:1Cis & $12.50 \pm 0.20$ \\
C22:0 & $2.90 \pm 0.06$ \\
Total saturated & $1.90 \pm 0.02$ \\
Total unsaturated & $1.50 \pm 0.05$ \\
\hline
\end{tabular}

\section{Disc ussion}

Jiroft is a city which located at 28.4166700 (latitude in decimal degrees), and 57.7500000 (longitude in decimal). Jiroft is about 650-metres above the sea level and its weather is very warm in summer and moderate in winter.

Cavalheiro et al. ( 2015) reported the amount of determined CP, FEE, and Ash contents of different OL cultivars, including Arbosana, Ascolano, Grappolo, Koroneiki, Negrinha do Freixó varieties from Southern Brazil (23). The amounts of CP, FEE and Ash were in the range of 10.50-13.10, 9.13-9.80 and 4.65-6 (DM\%), respectively. Also, the CP, EE, and Ash contents of olive leaves of a Spain variety have been reported (in order) as 7, 3.21 and 1.62 (DM\%) by García et al. (2003) (24); and 10, 5.64 and 12 (DM\%) by Molina-Alcaide and Yáñez-Ruiz, (2008) (25).

The ash quantity of olive leaf is considered higher than other vegetal products such as pumpkin and watermelon seed kernels $(3.21 \%$ and $3.6 \%$, respectively) (26). Molina-Alcaide and Yáñez-Ruiz, (2008) reported that the ADF and NDF contents of olive leaf were obtained in the range of (A review: many varaities) 30.2 and 40.6 (DM\%), respectively 
(25). These results are in agreement with the obtained results for the ADF and NDF of Mari variety. It was reported that the chemical composition of OLs depends on the year, season, variety, proportion of branches, storage condition, drying procedure, climatic conditions, moisture content, and degree of contamination with soil and oils $(27,28)$. It is well known that the mentioned parameters are so important factors which can be influenced on physicochemical properties of OL.

The amount of TPC of Mary variety OL was higher than that of reported for Chétoui variety 24.36 (29) and $28.82 \mathrm{mg} \mathrm{GAE} \mathrm{g}^{-1}$ (23), respectively. It may be depending on the climatic conditions and variety of OLs. For instance, Teleszko and Wojdyło, (2015) suggested that the synthesis of polyphenolic compounds in plants depends on the degree of sunlight exposure and water relations during the vegetation period (30). In addition, Tattini et al. (2004) found an interesting phenomenon, the Ligustrum vulgare leaves from the shaded side of a bush (light exposure 6\%), contained 3-fold less polyphenols than those of grown under full sunlight exposure (100\%) (31). Also, Abbeddou et al. (2011) reported that TPC of OL is higher than that of other agricultural by-products, including lentil straw, atriplex leaves, Olive cake and tomato pomace (32). The use of OL as animal feed is a common practice in dry and semi-dry areas (33) which use OL in animal diet, which improved animal products (milk and meat) quality by decreasing the lipid oxidation due to antioxidant activity of OLs phenolic compounds .

In addition, flavonoids are widely distributed groups of polyphenolic compounds which are identified in recent years as antioxidants in various biological systems. It is well known that one of the important effects of flavonoids is the scavenging of oxygen-derived free radicals, which can prevent damage caused by free radicals, including experimentally induced gastric mucosal injury. Several studies have shown the importance of flavonoids structure as antioxidants and anti-radical compounds (34). Paiva-Martins et al. (2014) reported that the TFC of OL (Portugal variety) was $2.17 \mathrm{mg} / \mathrm{g}$ of DM (35). Also, it was determined that TFC of a OL Tunisia variety was obtained in the range of 56.57 \pm 6.0 to $125.64 \pm 3.36$ by Salah et al. (2012) (36). The variation found in the flavonoid content of the OLs extract was related to the different methods applied for extraction of flavonoid (extraction technique, solvent nature and time of extraction) and also the effect of sample origin. Finally, both flavonoid and phenolic compounds from olive leaf are known to have diverse biological activities and may also be responsible for the pharmacological actions of olive leaf or, at least, for synergistically reinforcing those actions (29).

Tannins are a complex group of water-soluble polyphenolic compounds arising from the metabolism of plants. Tannins are present in several feed resources used for ruminant feeding. Luciano et al. (2009) reported that tannin improved colour stability of lamb meat through antioxidant properties (37). The amount of OL tannins was reprted $3.16 \mathrm{mg} / \mathrm{g}$ of DM by Abbeddou et al. (2011), which is much lower than the obtained result of the present research (32). This result depends on the natural climatic conditions of the varieties.

It is well known that the DPPH assay has been widely used to evaluate the free radicals, scavenging ability of various natural products with antioxidant properties and has been accepted as a model compound for free radicals originating in lipids (38). The results of DPPH radical scavenging assay revealed that the extracts by hydrogen and/or electron donation, might prevent reactive radical species from reaching biomolecules such as lipoproteins, polyunsaturated fatty acids (PUFA), DNA, amino acids, proteins and sugars in susceptible biological and food system (21). The antioxidant activity of OL extract (variety of Sevillano, Lorestan, Iran) was $38.21 \%$ which is reported by Mohagheghi et al. (2011) (39). This may be related to the higher amount of oleuropein content of Mari OL. Also, lee et al. (2009) reported the antioxidant activity of alcholic extract of $\mathrm{OL}$ is associated with high levels of phenolic compounds such as oleuropein (38). Also, Benavente-Garcia et al. (2000) reported that synergy between flavonoid, oleuroposide and phenol leads to greater antioxidant activity than vitamins $\mathrm{C}$ and $\mathrm{E}$ (40).

It was reported that the quality and quantity of different polyphenol compounds present in OL extract depend on cultivar and process of OL after harvesting (41). Recent research demonstrated that polyphenolic compounds in OL are responsible for many biological activities such as antioxidant, anti-inflammation, antimicrobial, anti-viral, anticancer and also 
cardioprotective effects (42). The main polyphenolic compound in OL is oleuropein (41). The content of oleuropein in OL is high and is approximately 8 to $14 \%$ of dried leave weight (43). Result of this research showed that the amount of oleuropein was $8306.9 \mu \mathrm{g} / \mathrm{g}$ dried OL which constitued $40.5 \%$ of total concentration of polyphenolic compounds existed in Mari OL. The amounts of OL oleuropein repoted by Garcia et al. (2003) (24) and Dekanski et al. 2009 (44) were $24.54 \%$ and $19.8 \%$ of total concentration of present polyphenolic compounds, respectively. Among the existed phenolic compounds in olive oil, oleuropein and their derivative from its hydrolysis have the most biological importance. Oleuropein have several drug effects, including antioxidant, antiinflammation, anti-microbial, anti-viral, anticancer effects (45). Furthermore, oleuropein also have cardioprotective, anti ischemic anemia and fat decreasing effects (46). The quantifed and identified polyphenolic compounds by Garcia et al. (2003) were oleurocid (oleuropein and verbascosid), flavon (luteolin and apigenin), flavonol (rutin), flavan-3-OL (catechin) andsubstituted phenol (tyrosol, hydroxyl tyrosol, vanillin, vanillic and caffeic acid) (24).

The polyunsaturated fatty acids, including the omega-3 and omega- 6 families detected in the plants constitute an important class of phytochemicals due to their generalized beneficial health effects (47). Linoleic acid has beneficial properties for the skin, including anti-inflammatory, acne reduction and moisture retention properties (48). Many researchers have found evidence that linoleic acid is related to a lower risk of cardiovascular diseases (49). Thus, the olive leaf extracts containing polyunsaturated fatty acids, constitute a potential source of fatty acids which can be used to manufacture dietary supplements.

A few studies have been carried out to evaluate the fatty acid composition of OL. For instance, Tsiplakou and Zervas, (2008) reported that the following values of fatty acids: C14:0 $(2.1 \pm 0.1 \%), \mathrm{C} 16: 0(21.0 \pm$ $0.51 \%), \mathrm{C} 18: 0(2.4 \pm 0.06 \%), \mathrm{C} 18: 1(12.8 \pm 0.36 \%)$, $\mathrm{C} 18: 2 \mathrm{n}: 6 \mathrm{c}(13.1 \pm 0.79 \%)$, and $\mathrm{C} 18: 3 \mathrm{n}: 3$ (37.0 \pm $0.66 \%$ ) for OL (Greece variety) (50). Also, Cavalheiro et al. (2015) reported the following value of fatty acids: C14:0 (1.54\%), C16:0 (27.5\%), C18:0 (5.55\%), C18:1 (21.5\%), C18:2n:6c (8.26\%), C18:3n:3 (41.30\%) and C20:0 (3.26\%) for Brazilian varieties (including, Arbosana, Ascolano, Grappolo,
Koroneiki, Negrinha do Freixó) (23). The results showed that $\mathrm{C} 16: 0 \quad(23.30 \pm 0.15 \%), \quad \mathrm{C} 18: 1$ $(21.80 \pm 0.40 \%), \quad \mathrm{C} 18: 2 \mathrm{n}: 6 \mathrm{c} \quad(27.20 \pm 0.33 \%), \quad$ and $\mathrm{C} 18: 3 \mathrm{n}: 3(12.50 \pm 0.20 \%)$ were the major fatty acids in the studied OL. Comparison of fatty acids composition of this variety with others showed differences in the amounts of C18:2n:6c (8.26\%), C18:3n:3 which can be related to the variety, climate condition, drying procedure and oil content reported by literatures previously $(25,27)$.

In addition, adding olive leaf into animal feed increased unsaturated fatty acids and reduced saturated fatty acids in animal milk. Tsiplakou and Zervas, (2008) found that the feeding of OL to sheep and goat increased the content of conjugated linoleic acids (cis9-trans11 a Polyunsaturated fatty acid) which is very beneficial for human health.

\section{Conclusion}

OLs are a rich source of the valuable polyphenolic compounds specially oleuropein that have high antioxidant and anticancer activities. Also, they are a good source of beneficial unsaturated FAs. So, OLs can be used as a new and potential antioxidant source for improving human health or as an animal feed for increasing the quality of animal products (milk and meat). In addition, in vivo experiments on the antioxidant effects of OLs would be essential.

\section{Financial disclosure}

The authors declared no financial interest.

\section{Funding/Support}

The study did not receive any financial support.

\section{References}

1. Rahmanian N, Jafari SM, Wani TA. Bioactive profile, dehydration, extraction and application of the bioactive components of olive leaves. Trends Food Sci Technol. 2015;42(2):150-72.

2. Farag R, El-Baroty G, Basuny AM. Safety evaluation of olive phenolic compounds as natural antioxidants. Int J Food Sci Nutr. 2003;54(3):159-74.

3. Cicerale S, Lucas L, Keast R. Antimicrobial, antioxidant and anti-inflammatory phenolic activities in extra virgin olive oil. Curr. Opin. Biotechnol. 2012;23(2):129-35.

4. Achat S, Tomao V, Madani K, Chibane M, Elmaataoui M, Dangles O, et al. Direct enrichment of olive oil in oleuropein by ultrasound-assisted maceration at laboratory and pilot plant scale. Ultrason Sonochem. 2012;19(4):777-86. 
5. Mancebo-Campos V, Salvador MD, Fregapane G. Antioxidant capacity of individual and combined virgin olive oil minor compounds evaluated at mild temperature (25 and $40 \mathrm{C}$ ) as compared to accelerated and antiradical assays. Food Chem. 2014;150:374-81.

6. Carrera-González M, Ramírez-Expósito M, Mayas M, Martínez-Martos J. Protective role of oleuropein and its metabolite hydroxytyrosol on cancer. Trends Food Sci Technol. 2013;31(2):92-9.

7. Fuentes E, Palomo I. Antiplatelet effects of natural bioactive compounds by multiple targets: Food and drug interactions. J Funct Foods. 2014;6:73-81.

8. Rubió L, Serra A, Macià A, Piñol C, Romero M-P, Motilva M-J. In vivo distribution and deconjugation of hydroxytyrosol phase II metabolites in red blood cells: a potential new target for hydroxytyrosol. J Funct Foods. 2014;10:139-43.

9. Sepporta MV, Fuccelli R, Rosignoli P, Ricci G, Servili M, Morozzi G, et al. Oleuropein inhibits tumour growth and metastases dissemination in ovariectomised nude mice with MCF-7 human breast tumour xenografts. J Funct Foods. 2014;8:269-73.

10. Camo J, Beltrán JA, Roncalés P. Extension of the display life of lamb with an antioxidant active packaging. Meat Sci. 2008;80(4):1086-91.

11. Erbay Z, Icier F. The importance and potential uses of olive leaves. Food Rev Int. 2010;26(4):319-34.

12. D’Arrigo M, Hoz L, Lopez-Bote C, Cambero I, Pin C, Ordonez J. Effect of dietary linseed oil on pig hepatic tissue fatty acid composition and susceptibility to lipid peroxidation. Nutr Res. 2002;22(10):1189-96.

13. Abbeddou S, Rischkowsky B, Richter E, Hess H, Kreuzer M. Modification of milk fatty acid composition by feeding forages and agro-industrial byproducts from dry areas to Awassi sheep. J Dairy Sci. 2011;94(9):4657-68.

14. Botsoglou E, Govaris A, Christaki E, Botsoglou N. Effect of dietary olive leaves and/or $\alpha$-tocopheryl acetate supplementation on microbial growth and lipid oxidation of turkey breast fillets during refrigerated storage. Food Chem. 2010;121(1):17-22.

15. AOAC Official Method 926.12. Moisture and Volatile Matter In Oils and Fats. (2000).

16. AOAC Official Method 942.05., Determination of ash in animal feed. (2000).

17. AOAC Official Method 2001.11 Protein (crude) in animal feed, forage (plant tissue), grain and oilseeds. AOAC International Gaithersburg, MD; 2009.

18. Thiex NJ, Anderson S, Gildemeister B. Crude fat, diethyl ether extraction, in feed, cereal grain, and forage (Randall/Soxtec/submersion method): Collaborative study. J AOAC Int. 2003;86(5):888-98.

19. Van Soest Pv, Robertson J, Lewis B. Methods for dietary fiber, neutral detergent fiber, and nonstarch polysaccharides in relation to animal nutrition. J Dairy Sci. 1991;74(10):3583-97.

20. Council I. Determination of biophenols in olive oils by HPLC. COI.

21. Arabshahi-D S, Devi DV, Urooj A. Evaluation of antioxidant activity of some plant extracts and their heat, $\mathrm{pH}$ and storage stability. Food Chem. 2007;100(3):1100-5.

22. Mohammed S, Manan FA. Analysis of total phenolics, tannins and flavonoids from Moringa oleifera seed extract. J Chem Pharm Res. 2015;7(1):135-7.

23. Cavalheiro CV, Picoloto RS, Cichoski AJ, Wagner R, de Menezes CR, Zepka LQ, et al. Olive leaves offer more than phenolic compounds-Fatty acids and mineral composition of varieties from Southern Brazil. Ind Crops Prod. 2015;71:122-7.

24. García AMn, Moumen A, Ruiz DY, Alcaide EM. Chemical composition and nutrients availability for goats and sheep of two-stage olive cake and olive leaves. Anim. Feed Sci. Technol. 2003;107(1):61-74.

25. Molina-Alcaide E, Yáñez-Ruiz D. Potential use of olive by-products in ruminant feeding: A review. Anim. Feed Sci. Technol. 2008;147(1):247-64.

26. El-Adawy TA, Taha KM. Characteristics and composition of different seed oils and flours. Food chem. 2001;74(1):47-54.

27. Delgado-Pertiñez M, Gómez-Cabrera A, Garrido A. Predicting the nutritive value of the olive leaf (Olea europaea): digestibility and chemical composition and in vitro studies. Anim. Feed Sci. Technol. 2000;87(3):187-201.

28. Martín-García A, Molina-Alcaide E. Effect of different drying procedures on the nutritive value of olive (Olea europaea var. europaea) leaves for ruminants. Anim. Feed Sci. Technol. 2008;142(3):317-29.

29. Abaza L, Youssef NB, Manai H, Haddada FM, Methenni K, Zarrouk M. Chétoui olive leaf extracts: influence of the solvent type on phenolics and antioxidant activities. grasas y aceites. 2011;62(1):96104.

30. Teleszko M, Wojdyło A. Comparison of phenolic compounds and antioxidant potential between selected edible fruits and their leaves. J Funct Foods. 2015; 14:736-46.

31. Tattini M, Galardi C, Pinelli P, Massai R, Remorini D, Agati G. Differential accumulation of flavonoids and hydroxycinnamates in leaves of Ligustrum vulgare under excess light and drought stress. New Phytol. 2004;163(3):547-61.

32. Abbeddou S, Rihawi S, Hess H, Iñiguez L, Mayer A, Kreuzer M. Nutritional composition of lentil straw, vetch hay, olive leaves, and saltbush leaves and their digestibility as measured in fat-tailed sheep. Small Rumin Res. 2011;96(2):126-35. 
33. Cabrera-Gomez A, Garrido A, Guerrero J, Ortiz V. Nutritive value of the olive leaf: effects of cultivar, season of harvesting and system of drying. J Agric Sci . 1992;119(2):205-10.

34. Shahidi F, Ambigaipalan P. Phenolics and polyphenolics in foods, beverages and spices: Antioxidant activity and health effects-A review. J Funct Foods. 2015;18:820-97.

35. Paiva-Martins F, Barbosa S, Silva M, Monteiro D, Pinheiro V, Mourão JL, et al. The effect of olive leaf supplementation on the constituents of blood and oxidative stability of red blood cells. J Funct Foods. 2014;9:271-9.

36. Salah MB, Abdelmelek H, Abderraba M. Study of phenolic composition and biological activities assessment of olive leaves from different varieties grown in Tunisia. Med chem. 2012;2(5):107-11.

37. Luciano G, Monahan F, Vasta V, Biondi L, Lanza M, Priolo A. Dietary tannins improve lamb meat colour stability. Meat sci. 2009;81(1):120-5.

38. Lee O-H, Lee B-Y, Lee J, Lee H-B, Son J-Y, Park C-S, et al. Assessment of phenolics-enriched extract and fractions of olive leaves and their antioxidant activities. Bioresour Technol. 2009;100(23):6107-13.

39. Mohagheghi F, Bigdeli MR, Rasoulian B, Hashemi P, Pour MR. The neuroprotective effect of olive leaf extract is related to improved blood-brain barrier permeability and brain edema in rat with experimental focal cerebral ischemia. Phytomedicine. 2011; 18(2): $170-5$.

40. Benavente-Garcia O, Castillo J, Lorente J, Ortuno A, Del Rio J. Antioxidant activity of phenolics extracted from Olea europaea L. leaves. Food Chem. 2000;68(4):457-62.

41. Paiva-Martins F, Correia R, Félix S, Ferreira P, Gordon $\mathrm{MH}$. Effects of enrichment of refined olive oil with phenolic compounds from olive leaves. J Agric Food Chem. 2007;55(10):4139-43.

42. Talhaoui N, Taamalli A, Gómez-Caravaca AM, Fernández-Gutiérrez A, Segura-Carretero A. Phenolic compounds in olive leaves: Analytical determination, biotic and abiotic influence, and health benefits. Food Res Int. 2015;77:92-108.

43. Silva S, Gomes L, Leitao F, Coelho A, Boas LV. Phenolic compounds and antioxidant activity of Olea europaea L. fruits and leaves. Food Sci Technol Int. 2006;12(5):385-95.

44. Dekanski D, Janicijevic-Hudomal S, Ristic S, Radonjic NV, Petronijevic ND, Piperski V, et al. Attenuation of cold restraint stress-induced gastric lesions by an olive leaf extract. Gen Physiol Biophys. 2009;28:135-42.

45. Tripoli E, Giammanco M, Tabacchi G, Di Majo D, Giammanco S, La Guardia M. The phenolic compounds of olive oil: structure, biological activity and beneficial effects on human health. Nutr Res Rev. 2005;18(1):98112.

46. Andreadou I, Iliodromitis EK, Mikros E, Constantinou M, Agalias A, Magiatis P, et al. The olive constituent oleuropein exhibits anti-ischemic, antioxidative, and hypolipidemic effects in anesthetized rabbits. J Nutr. 2006;136(8):2213-9.

47. Guimarães R, Barros L, Carvalho AM, Sousa MJ, Morais JS, Ferreira IC. Aromatic plants as a source of important phytochemicals: Vitamins, sugars and fatty acids in Cistus ladanifer, Cupressus lusitanica and Eucalyptus gunnii leaves. Ind Crops Prod. 2009;30(3):427-30.

48. Darmstadt G, Mao-Qiang M, Chi E, Saha S, Ziboh V, Black R, et al. Impact of topical oils on the skin barrier: possible implications for neonatal health in developing countries. Acta Paediatr. 2002;91(5):546-54.

49. Connor WE. Importance of $n-3$ fatty acids in health and disease. Am J Clin Nutr. 2000;71(1):171S-5S.

50. Tsiplakou E, Zervas G. The effect of dietary inclusion of olive tree leaves and grape marc on the content of conjugated linoleic acid and vaccenic acid in the milk of dairy sheep and goats. J Dairy Res. 2008;75(3):2708 .

51. Manai-Djebali HD, Krichène Y, Ouni L, Gallardo J, Sánchez E, Osorio D, et al. Chemical profiles of five minor olive oil varieties grown in central Tunisia. Journal of Food Composition and Analysis 2012; 27 (2):109-119.

52. López-Miranda JF, Pérez-Jiménez E, Ros R, De Caterina L, Badimón MI, Covas E, et al. Olive oil and health: summary of the II international conference on olive oil and health consensus report, Jaén and Córdoba (Spain) 2008. Nutrition, metabolism and cardiovascular diseases 2010; 20 (4):284-294. 